\title{
Dynamic Hotelling Duopoly with Linear Transportation Costs ${ }^{1}$
}

\author{
Luca Lambertini \\ Department of E conomics \\ University of Bologna \\ Strada Maggiore 45 \\ 40125 Bologna, Italy \\ fax +39-051-2092664 \\ e-mail lamberti@spbo.unibo.it
}

October 9, 2000

II thank Giacomo Calzolari, R oberto Cellini, Vincenzo Denicolò and Dan Sasaki for helpful discussion. The usual disclaimer applies. 


\begin{abstract}
A bstract
I investigate a spatial duopoly model with linear transportation costs as a dixerential game where product dixerentiation is the result of ..rms' $R \& D$ investments. T wo related results obtain, i.e., (i) the steady state $R \& D$ investment (product dixerentiation) is negatively (positively) related to the cost of capital and time discounting; and (ii) if time discounting and the cost of capital are suф ciently high, the amount of dixerentiation observed in steady state is su $\$$ ciently large to ensure the existence of a unique pure-strategy price equilibrium with prices above marginal cost.
\end{abstract}

\title{
J .E.L. Classi..cation: L13, 031
}

Keywords: horizontal dixerentiation, dixerential games, steady state, $R \& D$ 


\section{Introduction}

Ever since Hotelling's (1929) seminal contribution, the role of product differentiation as a remedy to the fragility of market equilibrium under price competition has represented a core issue in the ..eld of industrial organization.

However, under horizontal product dixerentiation, an established result is that a pure-strategy equilibrium in prices may not always exist (see, inter alia, d'A spremont et al., 1979; Gabszewicz and Thisse, 1986; E conomides, 1986; Anderson, 1988). M ore precisely, a subgame perfect equilibrium with prices greater than marginal cost may fail to exist, because ..rms' location choices drive prices to marginal cost when transportation costs are linear (or not suc ciently convex) in the distance between the generic consumer and the ..rm he decides to patronise. This non-existence problem has generated a stream of literature proposing several remedies, either by adopting nonlinear transportation cost functions (d'A spremont et al., 1979; Stahl, 1982; Economides, 1986) or by adopting the Stackelberg equilibrium as the solution concept (A nderson, 1987), or by choosing appropriate distribution functions for the population of consumers (de Palma et al., 1985; Neven, 1986), or a mix thereof (Tabuchi and Thisse, 1995; Lambertini, 1997, 2000). ${ }^{1}$

In this paper, I illustrate an alternative route, which consists in nesting Hotelling's linear transportation cost problem into a dixerential game with $R \& D$ for product innovation. This entails that location is no longer a control variable, since product design is the outcome of ..rms' intertemporal $R \& D$

\footnotetext{
${ }^{1}$ For exhaustive accounts of the debate, see Caplin and Nalebux (1991); A nderson et al. (1992); A nderson et al. (1997).
} 
exorts, i.e., investment is the control variable while location (and therefore product dixerentiation) becomes a state variable which varies over time. I show that there are conditions on time preferences (and the cost of capital) such that ..rms choose long run equilibrium locations where there exists no undercutting incentive, and therefore a price equilibrium does exist with prices above marginal production costs in correspondence to a steady state degree of dixerentiation which is not minimum. This result is derived under both open and closed loop solutions. There emerges that the range of time discounting (or the rental price of capital) wherein the game produces a price equilibrium in pure strategies is wider under the closed loop solution than under the open loop solution.

The reminder of the paper is structured as follows. The basic model and the non-existence problem are introduced in section 2. Section 3 describes the dixerential game. Section 4 contains concluding remarks.

\section{The basic setup}

Examine ..rst the static problem, as originally formulated by Hotelling (1929). I consider a market for horizontally dixerentiated products where consumers are uniformly distributed with unit density along the unit interval [0;1], the linear city. T wo single-product pro..t-maximising ..rms, labelled as 1 and 2, sell a dixerentiated good along the segment. Product locations are $x_{1}$ and $\mathrm{x}_{2}$ : On the basis of the symmetry of the model, I assume that $\mathrm{x}_{1} \cdot 1=2$ and $x_{2}, 1=2:^{2}$ The generic consumer located at a $2[0 ; 1]$ buys one unit of the

\footnotetext{
${ }^{2}$ This assumption that ..rm 1 (respectively, 2) is located to the left (right) of $1 / 2$ is meant to exclude the possibility of leapfrogging by either ..rm. As in Tabuchi and Thisse
} 
good to maximise his utility:

$$
U=s \text { i } p_{i} \text { i } c j x_{i} \text { i aj, } 0 ; \quad i=1 ; 2
$$

where $x_{i}$ and $p_{i}$ are ..rm's $i$ location and mill price, respectively, and $c>0$ is the transportation cost rate. In the remainder of the paper, I suppose that the reservation price $s$ is never binding, so that full market coverage always obtains. One can easily derive from (1) the location $\boldsymbol{b} \mathbf{2}\left(\mathrm{x}_{1} ; \mathrm{x}_{2}\right)^{3}$ of the consumer who is indixerent between the two goods at generic price and location pairs,

$$
s \text {; } p_{1} \text { i } c\left(\boldsymbol{b}_{\text {; }} x_{1}\right)=s \text {; } p_{2} \text { i } c\left(x_{2} \text {; } \quad \mathbf{b}\right) \text {; }
$$

as well as the demand functions:

$$
y_{1}=\frac{p_{2} i p_{1}+c\left(x_{1}+x_{2}\right)}{2 c} ; y_{2}=\frac{p_{1} i p_{2}+c\left(2 ; x_{1} i x_{2}\right)}{2 c}:
$$

Unit production cost is assumed to be constant and equal across varieties. Without further loss of generality, I normalise it to zero. Therefore, ..rm i's pro..t function is $1 / 4=p_{i} y_{i}$ :

Firms play noncooperatively a two-stage game where they move simultaneously at both stages. In the ..rst, ..rms choose locations, in the second they choose prices. The solution concept is the subgame perfect equilibrium by backward induction.

(1995) and Lambertini (1997), ..rms are allowed to locate also outside the city boundaries. This assumption is discussed in section 3 .

${ }^{3}$ If this condition is not met, e.g., if the indixerence condition is written under the assumption that a $2\left(\mathrm{x}_{2} ; 1\right]$; then it can be immediately veri..ed that the location of the indixerent consumer is unde.ned. 
First order conditions (FOCS) at the market stage yield the following candidate equilibrium prices:

$$
p_{1}^{\alpha}=\frac{c\left(2+x_{1}+x_{2}\right)}{3} ; p_{2}^{\alpha}=\frac{c\left(4 ; x_{1} i x_{2}\right)}{3}:
$$

The above prices are strictly positive for all $x_{1} 2[0 ; 1=2]$ and $x_{2} 2[1=2 ; 1]$ : However, as proved by d'A spremont et al. (1979), if ..rms locate in $[1=4 ; 3=4]$; there exists an incentive for each of them to undercut the rival's price by setting:

$$
p_{i}^{u}=p_{j} \text { i cjx } x_{i} x_{j} j ; \text { for all } p_{j}>0:
$$

That is, demand functions are discontinuous at $p_{i}^{u}$; since at that price, given any $p_{j} ; . . r m$ i becomes a monopolist and ..rm $\mathrm{j}$ is driven out of business. Therefore, the price pair (4) cannot be an equilibrium outcome for all locations. Moreover, at the ..rst stage we have:

$$
\frac{@ / 4}{@ x_{1}}>0 ; \frac{@ / 4}{@ x_{2}}<0
$$

for all admissible $f x_{1} ; x_{2} g$; which entails that ..rms are lead towards the midpoint by pro..t incentives at the ..rst stage of the game. That is, the choice of location drives ..rms precisely into the segment where the purestrategy equilibrium with prices above marginal production cost (i.e., in this setting, with positive prices) fails to exist. ${ }^{4}$ By altering the transportation cost function from linear to quadratic, d'Aspremont et al. (1979) obtain a tractable model where a unique pure-strategy price equilibrium exists for all location pairs. In particular, the adoption of quadratic disutility of transportation

\footnotetext{
${ }^{4}$ The price equilibrium always exists in mixed strategies (see Dasgupta and M askin, 1986; O sborne and Pitchik, 1987).
} 
eliminates the incentive to undercut, and equilibrium prices are zero if and only if dixerentiation is nil.

\section{The dixerential game}

The non-existence problem described above stems from the fact that, with linear transportation costs, the incentive to dixerentiate products is weaker than the incentive to move towards the middle of the market so as to increase the demand basin for a product. That is, ..rms are attracted by the median (and average) consumer. This creates a price war through undercutting, that drives equilibrium prices and pro.ts to zero. A possible remedy to this problem consists in making it costly for ..rms to design their respective products according to the preferences of the median consumer. This is what I propose here.

The instantaneous pro..t is $1 / 4(\mathrm{t})=\mathrm{p}_{\mathrm{i}}(\mathrm{t}) \mathrm{y}_{\mathrm{i}}(\mathrm{t}) \mathrm{i}^{1 / 1} \mathrm{k}_{\mathrm{i}}(\mathrm{t})$; where $\mathrm{k}_{\mathrm{i}}(\mathrm{t})$ is the amount of resources invested in $R \& D$ by ..rm i at time $t$; and $1 / 2$ is the rental price of capital, which in the remainder of the paper is assumed to be equal to the discount rate common to both ..rms. By symmetry, I focus upon the behaviour of ..rm 2. She can modify the location of her product through $R \& D$ investment according to:

$$
\frac{@ x_{2}(t)}{@ i t}=i \frac{k_{2}(t)}{1+k_{2}(t)} \phi x_{2}(t) ; \quad k_{2}(t), 0 ; x_{2}(0), 1:
$$

Notice that the condition $x_{2}(0), 1$ potentially allows for any degree of dixerentiation to emerge at the long-run equilibrium. The $R \& D$ technology de. ned by (7) exhibits decreasing returns to scale. ${ }^{5}$ The rationale behind (7)

\footnotetext{
${ }^{5}$ See Cellini and Lambertini (1999) for further discussion of (7).
} 
is that the $R \& D$ technology is shaped so as to reproduce the tendency for ..rms to locate towards the middle of the linear city, which characterises the static model described in section $2 .^{6}$

Firm 2 aims at maximizing the discounted value of her $¥$ ow of pro.ts

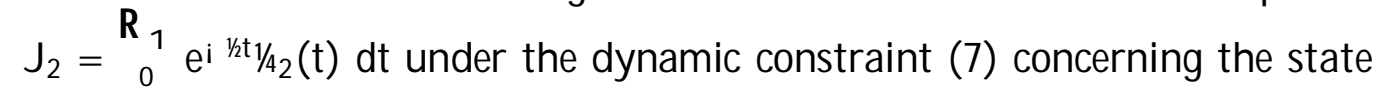
variable $\mathrm{x}_{2}(\mathrm{t})$. The control variables are $\mathrm{p}_{\mathrm{i}}(\mathrm{t})$ and $\mathrm{k}_{\mathrm{i}}(\mathrm{t})$. It is worth stressing that the undercutting incentive still exists within the second and third quartiles of the linear city. Yet, the fact that location $x_{i}(t)$ is no longer a control variable in the dynamic formulation of the duopoly game opens the possibility for the ..rms not to be axected by the undercutting problem in steady state.

The Hamiltonian function is:

$$
H_{2}(t)=e^{i \frac{1 / 5}{1 / 2}} \pitchfork \frac{p_{2}\left[p_{1} i p_{2}+c\left(2 i x_{1} i x_{2}\right)\right]}{2 c} ; 1 / k_{2}(t) i, 2(t) \frac{k_{2}(t) x_{2}(t)}{1+k_{2}(t)} ;
$$

where , $2(\mathrm{t})={ }^{1}{ }_{2}(\mathrm{t}) \mathrm{e}^{1 / 2} ;{ }_{2}(\mathrm{t})$ being the co-state variable associated to $\mathrm{x}_{2}(\mathrm{t})$ :

${ }^{6} \mathrm{~T}$ he relevant dixerence is that, in the present setting, relocation towards $1 / 2$ is costly. Alternatively, one could examine a technology such that

$$
\frac{@ \mathrm{x}_{1}(\mathrm{t})}{\text { (d }}<0 \text { and } \frac{\mathrm{x}_{2}(\mathrm{t})}{\text { @ } \mathrm{t}}>0 \text {; }
$$

pulling ..rms outwards as time goes by. This, however, would appear as a rather ad hoc assumption to the aim of preventing ..rms from entering the product range where the undercutting incentive destroys the pure-strategy price equilibrium. 


\subsection{The open loop solution}

In the open loop formulation of the game, the necessary and suc cient conditions for a path to be optimal are: ${ }^{7}$

$$
\begin{gathered}
\frac{@ H_{2}(t)}{@ p_{2}(t)}=\frac{p_{1}(t) ; 2 p_{2}(t)+c\left[2 ; x_{1}(t) ; x_{2}(t)\right]}{2 c}=0 ; \\
\frac{@ H_{2}(t)}{@ k_{2}(t)}=i \frac{\left.1 / 21+k_{2}(t)\right]^{2}+, 2(t) x_{2}(t)}{\left[1+k_{2}(t)\right]^{2}}=0 ; \\
\left.i \frac{@ H_{2}(t)}{@ x_{2}(t)}=\frac{@_{2}(t)}{@}\right) \frac{@_{2}(t)}{@_{t}}=, 2(t) \frac{k_{2}(t)}{1+k_{2}(t)}+1 / 2+\frac{p_{2}(t)}{2} ; \\
\lim _{t ! 1}{ }^{1}{ }_{2}(t) \phi x_{2}(t)=0:
\end{gathered}
$$

From the FOCs w.r.t. prices I obtain:

$$
p_{1}^{a}(t)=\frac{c\left[2+x_{1}(t)+x_{2}(t)\right]}{3} ; p_{2}^{a}(t)=\frac{c\left[4 i x_{1}(t) ; x_{2}(t)\right]}{3} ;
$$

which coincide with the optimal prices (4) characterising the static game.

From (10) I obtain:

$$
, 2(t)=i \frac{1 / 2\left[1+k_{2}(t)\right]^{2}}{x_{2}(t)}
$$

as well as

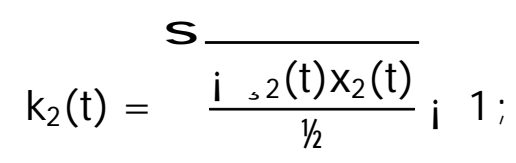

which allows me to establish:

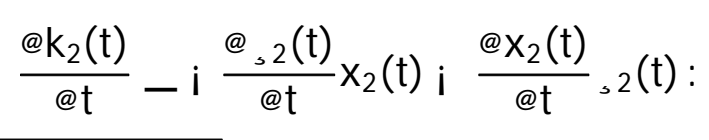

\footnotetext{
${ }^{7}$ The FOC w.r.t. price for ..rm 1 is:

$$
\frac{G \mathrm{H}_{1}(\mathrm{t})}{G \mathrm{p}_{1}(\mathrm{t})}=\frac{\mathrm{p}_{2}(\mathrm{t}) ; 2 \mathrm{p}_{1}(\mathrm{t})+\mathrm{c}\left[\mathrm{x}_{1}(\mathrm{t})+\mathrm{x}_{2}(\mathrm{t})\right]}{2 \mathrm{c}}=0
$$
}


Substituting (13) and (14) into (16), and using the symmetry condition $\mathrm{x}_{1}(\mathrm{t})=1 ; \mathrm{x}_{2}(\mathrm{t})$; I can rewrite (16) as follows:

$$
\frac{@ k_{2}(t)}{\text { (d }}-1 / 2\left[1+k_{2}(t)\right]^{2} i \frac{c}{2} x_{2}(t):
$$

The expression on the r.h.s. of (17) is equal to zero at:8

$$
k_{2}^{a}(t)=i 1+\frac{1}{1 / 2} \frac{c}{\frac{c}{2} x_{2}(t)} ;
$$

with

$$
\begin{aligned}
k_{2}^{a}(t) & >0 \text { for all } 1 / 2<\frac{r}{\frac{c}{2} x_{2}(t)} \\
\frac{G k_{2}(t)}{@ t} & >0 \text { for all } k_{2}(t)>k_{2}^{a}(t) \\
\frac{@ k_{2}(t)}{@ t} & <0 \text { for all } k_{2}(t) 2\left(0 ; k_{2}^{a}(t)\right):
\end{aligned}
$$

Obviously, $\frac{@ \mathrm{x}_{2}(\mathrm{t})}{@ \mathrm{t}}>0$ always. Expression (18) immediately yields the following intuitive result:

Lemma 1 The open loop steady state $R \& D$ investment is decreasing in the cost of capital and in intertemporal discounting.

Now observe that

$$
k_{2}^{a}(t)=0 i x x_{2}(t)=x_{2}^{a}=\frac{2}{c} 1 / 2
$$

where

$$
\frac{2}{c} 1 / 22{ }^{\mu} \frac{3}{4} ; 1 \text { for all } 1 / 22 \stackrel{\tilde{A} r}{\frac{3 c}{8}} ; \frac{{ }^{c}}{2} \text { : }
$$

\footnotetext{
${ }^{8}$ T he smaller root can be disregarded as it is always negative.
} 
The phase diagram is illustagted in gure 1 , where I describe a situation in which $\mathrm{x}_{2}(0)>3=4$ and $1 / 22 \quad \frac{\overline{3 c}}{8} ; \quad \frac{\bar{c}}{2}: 9$

Figure 1: Dynamics in the space $\left(\mathrm{x}_{2} ; \mathrm{k}_{2}\right)$

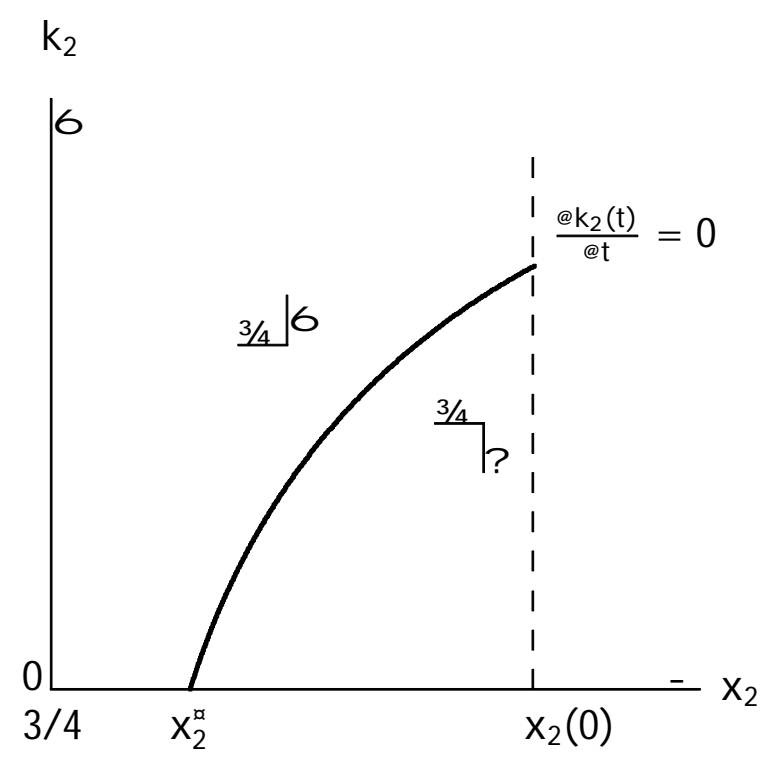

Considering the stability of the system, it remains to be stressed that, whenever $x_{2}^{a}>3=4$; it is a saddle. ${ }^{10}$ The above discussion can be summarised in the following:

Proposition 1 For all $1 / 2>\frac{r}{3 c}$; the open loop game reaches a steady state

\footnotetext{
${ }^{9}$ Whether $\mathrm{x}_{2}(0)$ (respectively, $\mathrm{x}_{1}(0)$ ) is larger or smaller than 1 (resp., 0 ) is irrelevant as to the graphical representation of the problem, as long as $x_{2}(0)$ (resp., $x_{1}(0)$ ) is larger (lower) than $3 / 4(1 / 4)$.

${ }^{10} \mathrm{~T}$ he complete proof is omitted, since this property immediately results from the dynamics of $x_{2}(t)$ and $k_{2}(t)$ as described by horizontal and vertical arrows in ..gure 1 .
} 
at

$$
k_{2}^{\alpha}=0 ; x_{2}^{\alpha}=\frac{2}{c} 1 / 2>\frac{3}{4}
$$

which is a saddle, where there exists no undercutting incentive.

The above Proposition produces the following Corollaries:

Corollary 1 The steady state degree of product dixerentiation is positively related with the cost of capital and time discounting.

Corollary 2 Given $\mathrm{x}_{2}(0), 1$; maximum dixerentiation obtains in steady state if $1 / 2=\frac{\bar{C}}{2}$.

The above property highlights that the dynamic model, where intertemporal investment is the rel evant control variable, is intrinsically dixerent from its static counterpart, where the ..rst order conditions w.r.t. locations generate the well known minimum dixerentiation principle. When product design becomes costly, then the presence of linear disutility of transportation does not necessarily induce ..rms to seek for the product preferred by the median (and average) consumer, which in turn triggers the undercutting process. This, obviously, happens when the parameter measuring the rental prices of capital as well as time discounting is suф ciently low to drive ..rms within the second and third quartiles of the linear city. Then, as a ..nal result, we have the following:

Corollary 3 For all $1 / 2>\frac{r}{3 c}$; the open loop solution of the game produces a unique price equilibrium in pure strategies, with strictly positive prices. 
As a complement to Corollary 3 , it is worth observing that the undercutting incentive still operates when $x_{1}^{a} 2[1=4 ; 1=2]$ and $x_{2}^{a} 2[1=2 ; 3=4]$; which happens for all $1 / 2<\quad \frac{\overline{3 c}}{8}$ : That is, when the cost of capital and time discounting are suф ciently low, ..rms are driven into the region where the price equilibrium in pure strategies does not exist.

\subsection{The closed loop solution}

The characterisation of the Markov (subgame) perfect equilibrium (MPE) under the closed loop solution usually requires solving the relevant B ellman equation. ${ }^{11}$ Given that the Hamiltonian problem de. ned in (8) is not written in a linear-quadratic form, the B ellman - Hamilton - J acobi suф cient conditions for a MPE cannot be solved. However, I am going to show that, in the present case, the necessary conditions of the closed loop formulation suф ce to characterise the MPE.

First order conditions are (9), (10), (12) and

$$
i \frac{@ H_{2}(t)}{@ \alpha_{2}(t)} ; \frac{@ H_{2}(t)}{@ p_{1}(t)}+\frac{@ p_{1}^{\mathrm{a}}(\mathrm{t})}{@ \mathrm{x}_{1}(\mathrm{t})}=\frac{@_{2}(\mathrm{t})}{@ \mathrm{t}} ;
$$

where the term $\frac{@ H_{2}(t)}{@ p_{1}(t)}+\frac{@ p_{1}^{b r}(t)}{@ x_{1}(t)}=\frac{p_{2}(t)}{4}$ describes the feedback exect which does not appear in the open loop formulation. ${ }^{12}$ The derivative $\frac{\varrho_{1}^{p r}(t)}{\varliminf_{1}(t)}$ is

\footnotetext{
${ }^{11}$ See B aşar and Olsder (1982, 19952), M ehlmann (1988), Fudenberg and Tirole (1991, pp. 520-36), Vives (1999, pp. 336-47), inter alia.

${ }^{12} \mathrm{~N}$ otice that

$$
\mathrm{i} \frac{\mathbb{d} \mathrm{H}_{2}(\mathrm{t})}{\mathbb{d} \mathrm{k}_{1}(\mathrm{t})} \pitchfork \frac{\mathbb{d} \mathrm{k}_{1}(\mathrm{t})}{\mathrm{Q} \mathrm{x}_{1}(\mathrm{t})}
$$

does not appear in (24), in that $\frac{\mathbb{G H} \mathrm{H}_{2}(\mathrm{t})}{\mathfrak{G} \mathrm{k}_{1}(\mathrm{t})}=0$ :
} 
calculated on the basis of ..rm 1's best reply function in the price space,

$$
p_{1}^{\mathrm{br}}(\mathrm{t})=\frac{\mathrm{p}_{2}(\mathrm{t})+\mathrm{c}\left(\mathrm{x}_{1}+\mathrm{x}_{2}\right)}{2} ;
$$

which is the solution to:

$$
\frac{@_{1}(t)}{\varliminf_{1}(t)}=\frac{@}{@_{1}(t)}\left(p_{1} y_{1}\right)=\frac{p_{2}(t) ; 2 p_{1}(t)+c\left(x_{1}+x_{2}\right)}{2 c}=0:
$$

Condition (24) yields:

$$
\frac{@_{2}(t)}{\text { (at }}=, 2(t)^{\mu} \frac{k_{2}(t)}{1+k_{2}(t)}+1 / 2+\frac{p_{2}(t)}{3}:
$$

The dynamics of $k_{2}(t)$ is de..ned as in (16), which now simpli..es as follows:

$$
\frac{\mathfrak{d} k_{2}(t)}{\mathfrak{G} t}-1 / 2\left[1+k_{2}(t)\right]^{2} ; \frac{c}{4} x_{2}(t):
$$

The only acceptable root of the r.h.s. of (28) is:

$$
\begin{aligned}
& k_{2}^{a}(t)=i 1+\frac{1}{2^{1 / 2}} p \frac{}{C X_{2}(t)} ; \\
& k_{2}^{a}(t)>0 \text { for all } 1 / 2<\frac{1}{2} p \overline{c x_{2}(t)} ;
\end{aligned}
$$

with qualitatively the same properties as outlined in (20-21) as well as in ..gure 1. Obviously, the result stated in Lemma 1 applies in the closed loop formulation as well. Now observe that

$$
k_{2}^{a}(t)=0 i x x_{2}(t)=x_{2}^{a}=\frac{4}{c} 1 / 2
$$

where

$$
\frac{3}{c_{1 / 2} 2} \mu_{\frac{3}{4} ; 1} \text { for all } 1 / 22 \frac{\tilde{A}_{p}}{\frac{3 c}{4}} ; \frac{r_{\frac{c}{2}}^{\#}}{} \text { : }
$$

By comparing (31) with (22), the following Lemma obtains: 
Lemma 2 The steady state degree of product dixerentiation is larger under the closed loop solution than under the open loop solution.

The above Lemma implies the ..nal result:

Proposition 2 The critical threshold of the discount rate (or the cost of capital) above which there exists a price equilibrium in pure strategies is lower under the closed loop solution than under the open loop solution.

As a ..nal remark, notice that, obviously, from (13) and given $x_{1}^{\alpha}+x_{2}^{\alpha}=1$; equilibrium prices (and consequently equilibrium outputs) are the same under both the open loop and the closed loop solution, i.e., $p_{1}^{\alpha}=p_{2}=c$ (and $y_{1}^{a}=y_{2}^{a}=1=2$.

\section{Concluding remarks}

I have reformulated the spatial duopoly model with linear transportation costs as a dixerential game where location is costly and therefore product dixerentiation is the result of ..rms' $R \& D$ decisions over time. I have characterised both the open loop and the closed loop solution. This has generated two related results. The ..rst is that the steady state $R \& D$ investment (product dixerentiation) is negatively (positively) related to the cost of capital and time discounting. The second is that, if time discounting and the cost of capital are suф ciently high, the amount of dixerentiation observed in steady state is suc ciently large to ensure the existence of a unique pure-strategy price equilibrium with prices above marginal cost. Product dixerentiation in steady state is larger under the closed loop solution than under the open 
loop solution. Consequently, the range of discount rates such that a pure strategy equilibrium exists is larger under the closed loop solution. 


\section{R eferences}

[1] Anderson, S.P. (1987), "Spatial Competition and Price Leadership", International J ournal of Industrial Organization, 5, 369-398.

[2] A nderson, S.P. (1988), "Equilibrium Existence in the Linear Model of Spatial Competition", E conomica, 55, 479-491.

[3] A nderson, S.P., de Palma, A., and Thisse, J .-F . (1992), Discrete Choice Theory of Product Dixerentiation, Cambridge, MA, MIT Press.

[4] A nderson, S.P., Goeree, J.K., and Ramer, R. (1997), “Location, Location, Location", J ournal of Economic Theory, 77, 102-127.

[5] Başar, T., and Olsder, G.J . (1982, 1995²), Dynamic Noncooperative Game Theory, San Diego, A cademic Press.

[6] Caplin, A., and Nalebux, B. (1991), “Aggregation and Imperfect Competition: On the Existence of Equilibrium", Econometrica, 59, 25-59.

[7] Cellini, R. and Lambertini, L. (1999), “A Dixerential Game Approach to Investment in Product Digerentiation", Discussion paper 99/5, Department of E conomics, University of Bologna (Rimini Centre).

[8] Dasgupta, P., and Maskin, E. (1986), The Existence of Equilibrium in Discontinuous Economic Games, II: Applications, Review of Economic Studies, 53, pp. 27-42.

[9] d'A spremont, C., Gabszewicz, J.J., and Thisse, J.-F. (1979), “On Hotelling's 'Stability in Competition"', Econometrica, 47, 1045-1050. 
[10] de Palma, A ., Ginsburgh, V ., Papageorgiou, Y ., and Thisse, J .-F . (1985), "T he Principle of Minimum Dixerentiation Holds Under Suф cient Heterogeneity", Econometrica, 53, 767-782.

[11] Economides, N. (1986), "Minimal and Maximal Dixerentiation in Hotelling's Duopoly", E conomics Letters, 21, 67-71.

[12] Fudenberg, D., and Tirole, J. (1991), Game Theory, Cambridge, MA, MIT Press.

[13] Gabszewicz, J J ., and Thisse, J .-F . (1986), "On the Nature of Competition with Dixerentiated Products", Economic J ournal, 96, 160-172.

[14] Hotelling, H. (1929), "Stability in Competition", Economic J ournal, 39, 41-57.

[15] Lambertini, L. (1997), "Unicity of the Equilibrium in the Unconstrained Hotelling M odel", Regional Science and Urban Economics, 27, 785-798.

[16] Lambertini, L. (2000), “Vertical Dixerentiation in a Generalized Model of Spatial Competition", Annals of Regional Science, forthcoming.

[17] MehImann, A. (1988), Applied Dixerential Games, New York, Plenum Press.

[18] Neven, D. (1986), “On Hotelling's Competition with Non-Uniform Consumer Distributions", E conomics Letters, 21, 121-126.

[19] Osborne, M.J ., and Pitchik, C. (1987), Equilibrium in Hotelling's M odel of Spatial Competition, Econometrica, 55, pp. 911-922. 
[20] Stahl, K. (1982), "Location and Spatial Pricing Theory with Nonconvex Transportation Cost Schedules", Bell J ournal of Economics, 13, 575582.

[21] Tabuchi, T ., and T hisse, J .-F . (1995), "A symmetric Equilibria in Spatial Competition", International J ournal of Industrial Organization, 13, 213227.

[22] Vives, X. (1999), Oligopoly Pricing. Old Ideas and New Tools, Cambridge, MA, MIT Press. 